\title{
ДОСЛІДЖЕННЯ СИСТЕМИ УПРАВЛІННЯ КОНВЕРТЕРНОГО ПРОЦЕСУ ЗА ЕНЕРГОЗБЕРІГАЮЧОЮ ТЕХНОЛОГІЕЮ
}

Анотація: В роботі проведено дослідження систем управління кисневоконвертерного процесу з ПІД-регулятором та регулятором нечіткої логіки. Встановлено, що процес нестаціонарний і залежить від часу та періодів продувки. В ході імітаційного моделювання налаштовано параметри регуляторів та досліджено якість регулювання за перехідним процесом.

Ключові слова: Ключові слова: киснево-конвертерний процес, металевий брухт, ПІД-регулятор, регулятор нечіткої логіки, Matlab, Simulink, імітаційне моделювання.

\section{Вступ}

Основним видом сталеплавильного виробництва як в Україні так і в світі є конвертерне. Плавка проводиться за рахунок внутрішніх фрізичних і хімічних джерел тепла, що вноситься основною складовою шихти - чавуном. Надлишок тепла дозволяє переробляти металевий брухт в кількості 20 - 27\% від металевої частини шихти [1]. Беручи до уваги, що щорічне утворення брухту сягає майже $50 \%$ від виробництва сталі, розроблено багато технологій для збільшення кількості брухту, що переробляеться. Ці технології направлені на використання зовнішніх джерел тепла [2]. В той же час у самому конвертерному процесі $є$ внутрішнє джерело тепла - конвертерні гази, які складаються на $90 \%$ з $\mathrm{CO}$ і на $10 \%$ з $\mathrm{CO}_{2}$, що визначається термодинамічними умовами процесу. Регулювання процесу в бік збільшення кількості $\mathrm{CO}_{2}$ майже еквівалентно збільшує кількість брухту, що перероблюється. Основним регулюючим діянням при цьому є відстань фурми, через яку подається кисень на продувку, над рівнем металевої ванни [3]. Проведені нами дослідження показали, що об'єкт є суттєво нестаціонарним, коефіцієнт передачі й постійні часу залежать від тривалості продувки, плавно змінюючись в окремі періоди плавки, з різкою зміною при переході від одного періоду до іншого [4]. Це порушувало нормальний процес регулювання стандартним ПІД-регулятором і приводило до виникнення значних похибок у непередбачуваний момент часу.

Робота виконувалась в НТУУ “Київський політехнічний інститут" за темою "Модель керування конвертерною плавкою по енергозберігаючій технології”, Державний реєстраційний номер $0112 \mathrm{U} 003476$.

(c) В.С. Богушевський, К.М. Зубова, 2014 


\section{Постановка задач дослідження}

Метою дослідження є підвищення точності роботи регулятора ступеню допалювання $\mathrm{CO}$ до $\mathrm{CO}_{2}$ у відхідних газах в порожнині конвертера зміною відстані фрурми над рівнем розплаву.

\section{Результати досліджень}

Передаточна фрункція об'єкта управління має вигляд класичної передаточної функції коливальної ланки, в якій вхідна величина відстань фурми до рівня спокійної ванни, а вихідна - ступінь окиснення вуглецю до $\mathrm{CO}_{2}$ [5]:

$$
W(s)=\frac{k_{H}^{\gamma_{C O}}}{T_{2}^{2} s^{2}+2 \varepsilon T_{1} s+1},
$$

де $k_{H}^{\gamma_{\mathrm{CO}}}=k_{v_{C}} \cdot k_{\gamma_{C O_{2}}}-$ коефріціент передачі по каналу відстань фурми до рівня спокійної ванни - ступінь окиснення вуглецю до $\mathrm{CO}_{2}$, $T_{1}=\left(T_{v_{C}}+T_{\gamma_{C O_{2}}}\right) / 2 \varepsilon$ і $T_{2}^{2}=T_{v_{C}} \cdot T_{\gamma_{C O_{2}}}-$ постійні часу; $\varepsilon-$ коефіціент демпфування, що дорівнюе 0,9918 . Тут $k_{v_{C}}, T_{v_{C}}-$ відповідно коефріціент передачі по каналу відстань фурми до рівня спокійної ванни - швидкість зневуглецювання, $m /(x \beta \times л)$, і постійна часу, $c ; k_{\gamma_{\mathrm{CO}_{2}}}, T_{\gamma_{\mathrm{CO}_{2}}}-$ відповідно коефіцієнт передачі по каналу швидкість зневуглецювання - ступінь окиснення вуглецю до $\mathrm{CO}_{2}, x \boldsymbol{x} / \mathrm{m}$ вуглецю і постійна часу, $c$.

Для спрощення розрахунків механізм переміщення фурми опишемо передаточною фрункцією інтегруючої ланки:

$$
W_{M}(s)=\frac{k_{M}}{s},
$$

де $k_{M}$ - коефіцієнт передачі, $c^{-1}$.

В цьому випадку вхід системи $u(\tau)=\alpha_{1}(\tau)$ - задана ступінь окиснення вуглецю до $\mathrm{CO}_{2}$, а вихід $x(\tau)=\alpha_{2}(\tau)$ - відпрацьований системою ступінь окиснення вуглецю до $\mathrm{CO}_{2}, m(\tau)$ - керуючий сигнал на виході регулятора, а система описуеться загальною передаточною функцією:

$$
W(s)=\frac{\alpha_{2}(s)}{m(s)}=\frac{\alpha}{s\left(s^{2}+b s+a\right)},
$$

де $b=2 \varepsilon \cdot T_{1} / T_{2}^{2} ; a=1 / T_{2}^{2} ; \alpha=k_{H}^{\gamma_{C O}} \cdot k_{M} \cdot a=k_{H}^{\gamma_{C O}} \cdot k_{M} / T_{2}^{2}$.

Коефіцієнти $a, b$ i $\alpha$ також залежать від часу продувки, описуються поліномами $3-5$ ступенів, коефіціенти яких змінюються в залежності від періоду продувки. Синтез системи управління з ПІДрегулятором (рис. 1) і оптимізацію коефіціента передачі й постійних часу провели в інтерактивній системі Matlab за допомогою пакету Simulink.

Система складена наступним чином. Похибка err, що поступае на вхід регулятора, представляе собою різницю між заданим 


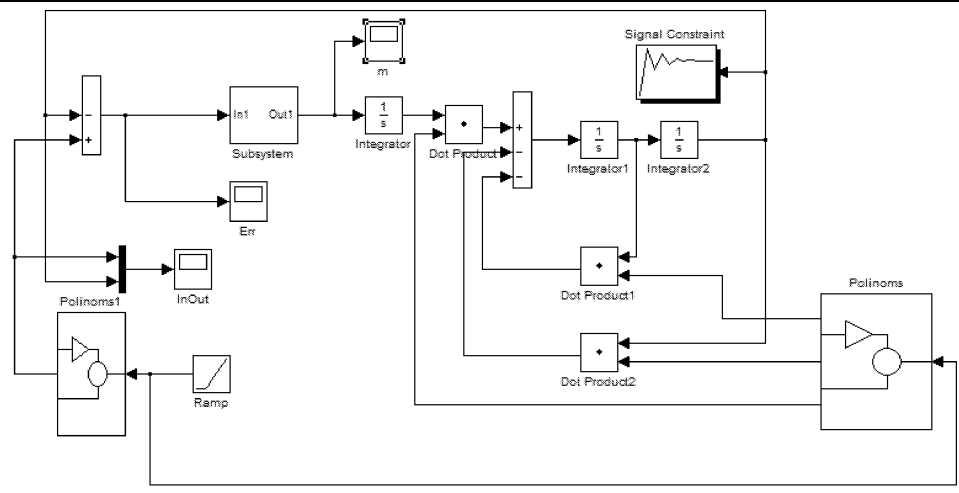

Рис. 1 - Блок-схема системи управління з ПІД-регулятором

значенням $\alpha_{1}(\tau)$ та отриманим в результаті регулювання: $\theta(\tau)=$ $\alpha_{1}(\tau)-\alpha_{2}(\tau)$. На вхід моделі поступае сигнал $m(\tau)$ з виходу блоку Integrator. Вихідний сигнал об'екта управління $\alpha_{2}(\tau)$ отримуемо на виході блоку Integ rator1. На виході блоку Polinoms формуються сигнали $a(\tau), b(\tau)$ i $\alpha(\tau)$, які у відповідних блоках множення Dot Product множаться на вихідний сигнал $m(\tau)$ відповідно записаному вище диференційному рівнянню (3). Зміну кількості $\mathrm{CO}_{2}$ зображено у блоці Polinoms1.

Моделювання показало, що середньоквадратичне відхилення ступеню допалювання окису вуглецю у двоокис становить $1,1 \%$ абс., причому найбільші похибки відносились до моментів переходу плавки з одного періоду до іншого.

Для зменшення похибки нами було введено в систему блок адаптації у реальному часі коефіцієнта передачі $k$ (рис. 2).

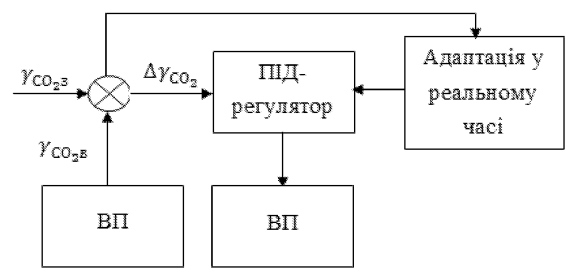

Рис. 2 - Система з ПІД-регулятором з модулем адаптації

Адаптацію проводили за середньо квадратичним відхиленням $\Delta \gamma_{C_{2} 2^{3}}$ виміряного ступеня допалення $C O \quad \Delta \gamma_{C_{2^{8}}}$ від заданого значення $\Delta \gamma_{\mathrm{CO}_{23}}$. Адаптацію проводять за формулою: 


$$
\sigma(n)=\sqrt{\frac{\sum_{i=n-N+1}^{n}\left(\Delta \gamma_{C O_{2}}(i)\right)^{2}}{N}}
$$

де $i$ - індекс поточного значення параметра, $N$ - кількість вимірів, що входять в масив.

Поточне відхилення обчислюють з дискретністю $0,25 \mathrm{c}$.

Розрахунок ведеться за $N$ значеннями відхилення $\Delta \gamma_{\mathrm{CO}_{2}}$ так, що кожний раз після $N$ етапів обчислення визначається нове значення $\sigma(n)$ (рис. 3). Робота починається з регламентації величини кроку $\Delta k$ зміни коефіцієнта передачі регулятора. Далі алгоритм працює за циклом аж до досягнення шуканого оптимуму.

На початку циклу розраховується фрактичне середньоквадратичне відхилення $\sigma(n)$. Потім воно порівнюеться із значеннями, що мали місце на $N$ і $2 N$ кроків назад. Залежно від результату порівняння $\Delta k$ розраховують так. Якщо при зміні $k$ середньоквадратичне відхилення майже не змінюеться, тобто $\sigma(n)-\sigma(n-N)<\varepsilon$, то величина кроку змінення подвоюеться. При виконанні цієї умови перевіряється правильність напрямку пошуку - якщо середньоквадратичне відхилення збільшуеться, тобто дія регулятора погіршується, то знак $\Delta k$ змінюють на зворотний. При правильному напрямку пошуку змінюють $k$ на величину $\Delta k$ доти, поки поблизу оптимуму не буде досягнуто співвідношення $\sigma(n-2 N)>\sigma(n-N)<$ $\sigma(n)$. Далі величина кроку зменшуеться вдвічі, а напрямок пошуку змінюеться на зворотний. Зміна коефіцієнта продовжується доти, поки середньоквадратичне відхилення не стане мінімальним і не буде досягнутий оптимум.

Після завершення оптимізації, як і раніше, на відстані $N$ кроків перевіряється розрахунок середньоквадратичного відхилення. Якщо при цьому буде встановлено, що воно істотно зросло, то цикл оптимізації запускається знову.

Система оптимізації, таким чином, автоматично оптимізує настройку ПІД-регулятора в процесі роботи. Оптимізація приводила до позитивного результату тільки для усунення невеликих збурень, що виникають в окремих періодах плавки. Середньоквадратичне відхилення похибки скоротилося до 0,8 \%абс. При переході від одного періоду до другого похибка регулювання, як і в стандартному ПІД-регуляторі, суттєво збільшувалася разом із тривалістю перехідного процесу.

Для зменшення похибки було прийняте рішення застосувати регулятор нечіткої логіки. За вхідні параметри обрано - поточний рівень фурми над розплавом, значення похибки регулювання масової частки $\mathrm{CO}_{2}$, швидкість та прискорення зміни похибки, а за вихідний параметр - задане значення рівня фурми над розплавом $[6,7]$. 


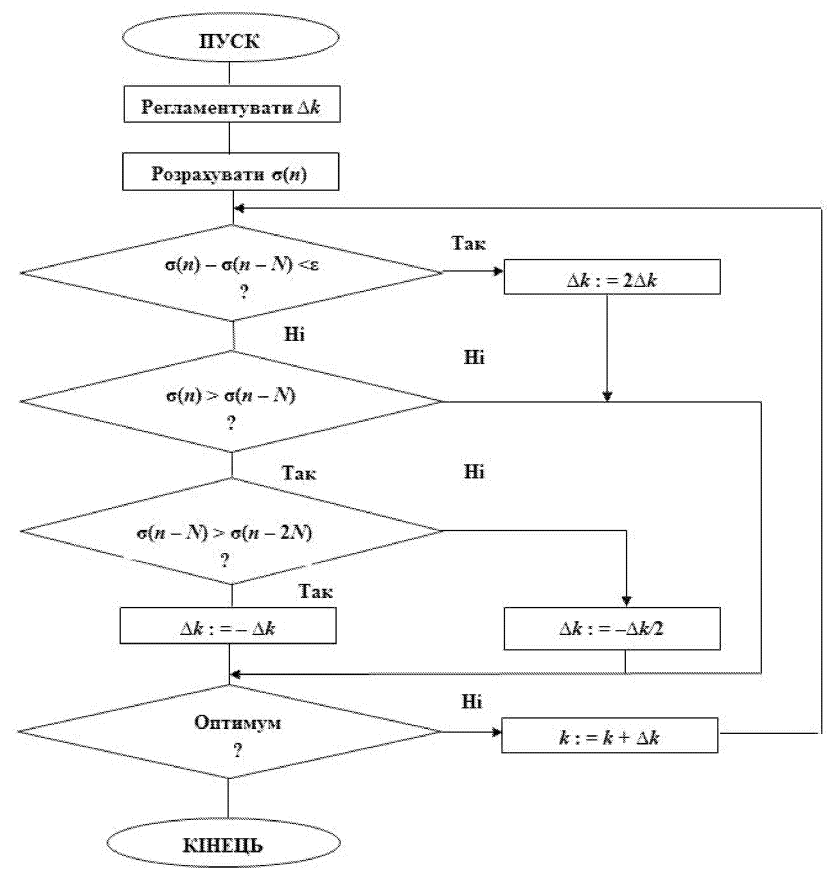

Рис. 3 - Блок-схема алгоритму адаптації

Побудову нечіткої моделі проводили в інтерактивній системі Matlab в пакеті Fuzzy Logic Toolbox. База включала 75 нечітких правил. Для моделювання розробили систему (рис. 4), яка аналогічна системі зображеній на рис. 1 та містить додатково АЦП, який характеризуеться кроком квантування, значення якого визначено в ході імітаційного моделювання, і дорівнюе $0.25 c$. Регулятор нечіткої логіки зображено у блоці Fuzzy Controller with Ruleviewer.

Оптимізацію нечіткого регулятора (НР) виконували шляхом зміни виду функцій приналежності (ФП) й кількості термів по кожному з чотирьох параметрів. При дослідженні встановлено, що найкращі результати показуе НР з ФП у вигляді трикутника, що перетинає весь діапазон зміни параметру. Гаусові та ФП у вигляді рівнобедреного трикутника неефективні для використання, що пов'язано можливо з різким переходом від одного терму до іншого, або недостатньою кількість термів та розроблених правил.

Подальші дослідження велись з використанням трикутних $Ф П$, що перетинають весь діапазон зміни параметру з трьома, п'ятьма та сімома термами. В результаті визначено, що найбільша похибка регулювання складае $2,0785 \%$ абс. при використанні НР з трьо- 


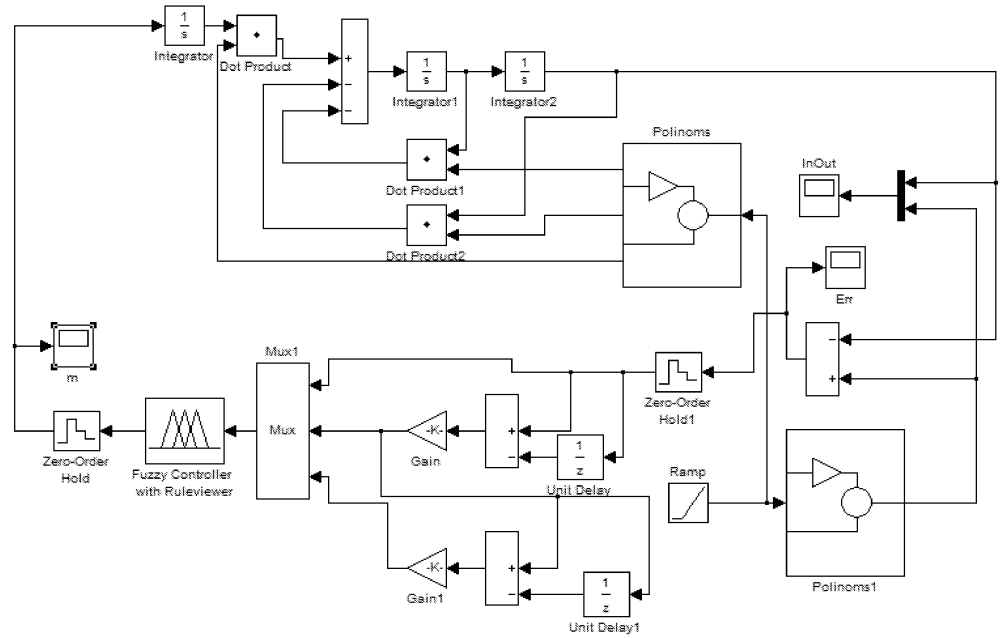

Рис. 4 - Система управління з нечітким регулятором

ма термами, а найменша похибка $\approx 0,7 \%$ абс. з сімома термами. $\mathrm{B}$ той же час в останньому випадку збільшуеться тривалість перехідного процесу, що досягає при переході від одного періоду плавки до іншого $40 \mathrm{c}$. В результаті було обрано 5 термів зміни по кожному параметру. Середньоквадратичне значення похибки при цьому склало $0,5 \%$ абс., що значно менше ніж у ПІД-регулятора з адаптацією. Зниження похибки відбулося в основному внаслідок кращого відпрацювання великих збурень при переході процесу з одного періоду до іншого.

\section{Висновки}

Застосування стандартних ПІД-регуляторів при регулюванні процесу допалення монооксиду вуглецю у ванні конвертера призводить до значних похибок, що визначається суттевою нестаціонарністю процесу. Введення блоку адаптації коефіцієнта передачі в реальному масштабі часу суттево скорочуе похибки, що зв'язані з невеликими збуреннями, майже не прискорюючи реакцію на великі збурення. Нечіткий регулятор не погіршує реакцію на невеликі збурення, але суттево поліпшуе відпрацювання великих збурень.

Застосування системи з нечітким регулятором дозволило збільшити кількість $\mathrm{CO}_{2}$ в газах, що відходять з конвертера, на $3-5 \%$, підвищивши кількість перероблюваного металевого брухту на 4 $6 \%$.

Подальші дослідження направлені на включення системи управління допалюванням $\mathrm{CO}$ у $\mathrm{CO}_{2}$ в АСУТП конвертерної плавки. 


\section{Список використаних джерел}

1. Основи металургійного виробництва металів і сплавів / за ред. Д. Ф. Чернеги, Ю. Я. Готвянського. - К.: Вища школа, 2006. $503 \mathrm{c}$.

2. Бойченко Б.М. Конвертерне виробництво сталі: теорія, технологія, якість сталі, конструкції агрегатів, рециркуляція матеріалів і екологія / Б. М. Бойченко, В. Б. Охотський, П. С. Харлашин: - Дніпропетровськ: РВА „Дніпро-ВАЛ”, 2004. - 454 с.

3. Богушевський В. C. Керування конвертерною плавкою в умовах енергозберігаючої технології / В. С. Богушевський, К. М. Зубова, В. Ю. Сухенко // Наукові вісті НТУу “КПІ”. - 2011. №5. - C. $65-69$.

4. Охотский В. Б. Использование многоканальных фурм в сталеплавильных процесах. Конвертер. / Охотский В. Б. // Металлургическая и горнорудная промышленность. - 2011. - №2. C. $28-29$.

5. Богушевський В. С. Математичне моделювання конвертерного процесу за енергозберігаючою технологією / В. С. Богушевський, К. М. Зубова // Технологічні комплекси. - 2013. - № 2 (8). - C. $32-38$.

6. Зубова K. М. Енергозберігаюча модель контролю окисненості шлаку // Матеріали XI міжнародної науково-практичної конференції "Спеціальна металургія: вчора, сьогодні, завтра", 18 квітня 2013 р., Київ. - С. $210-216$.

7. Богушевський В. С. Управління конвертерною плавкою в режимі енергозбереження / В. С. Богушевський, К. М. Зубова // Научно-техническая информация. - 2013. №1. - С. 52 - 56.

Отримано 03.09.2014 p. 